\title{
Water Framework Directive and Modelling Using PEGOPERA Simulation Software
}

\author{
Etienne Everbecq, Aline Grard, Pol Magermans, Jean-François Deliège \\ Aquapôle, University of Liège, B53 Campus Sart-Tilman, 4000 Liège, Belgium \\ E-mail:e.everbecq@uliege.be; Aquapole@uliege.be
}

Received: 12 April 2019; Accepted: 2 May 2019; Available online: 10 June 2019

\begin{abstract}
The Water Framework Directive 2000/60/EC (WFD) established a framework for community action in the field of water policy. To implement the WFD, the competent authorities for watershed management should use modelling techniques to establish, for example, the pressure/impacts relationship. The PEGOPERA modelling tool (composed of the water quality model PEGASE and a friendly Graphical User Interface), has been developed in order to be compliant with the requirements of the WFD. PEGASE is a physicochemical model describing the behaviour of whole river systems, at various scales, from tens to tens of thousands $\mathrm{km}^{2}$. The specificity of the model is its ability to work at a high spatial resolution not only for small river basins (water body level), but also for large drainage networks. Already used by several basin management competent authorities, the PEGOPERA modelling tool proved to be an efficient tool for helping in surface water management from local up to the international district level and is therefore an operational numerical tool for WFD implementation.
\end{abstract}

Keywords: Integrated modelling; PEGASE; PEGOPERA; Water quality assessment; WFD.

\section{Introduction}

The Water Framework Directive 2000/60/EC (WFD) established a framework for community action in the field of water policy. To implement the WFD, the competent authorities for watershed management have to perform some actions before specific dates. The actions include characterisation of surface waters, identification and characterisation of pressures, assessment of impacts, economic analysis of the water use (cost-efficiency of the measures), public consultation and production and publication of River Basin Management Plans (with quality objectives per "water body”).

However, the planning, the design and the management of the water resources systems become increasingly more and more complex [1], and inevitably involve impact prediction. Impact prediction involves modelling [2]. On the other hand, the WFD explicitly states "Member States may utilise modeling techniques to assist in such an assessment” [3].

Modelling is primarily relevant to establish the pressure/impacts relationship, and thus to estimate water quality improvement after implementing one or more measures and then to evaluate the effectiveness of measures prior to their real implementation. Modelling can also be helpful for water authorities to:

1) Estimate the water quality where (and when) no measurements are realised;

2) Establish the type-specific reference conditions for surface water body types;

3) Make balances sheets of pollutant loads into the rivers;

Due to the WFD requirements, models to be used need to have minimum characteristics, which include:

1) A spatial discretization which allows to simulates large river basins (International River Districts, taken into account effects of sub-basins) as well as small river basins (all basins $>10 \mathrm{~km}^{2}$, to simulates all the WFD waterbodies);

2) A complete and coherent representation of discharge loads (needed to establish the pressure/impact relationships);

3) A physically based water quality model (detailed representation of biogeochemical processes, not only the simple Streeter-Phelps model); efficiency and robustness are needed to establish an appropriate level of confidence;

4) Results matching (in both form and substance) the WFD requirements (i.e., results per water bodies)

5) A friendly user interface so that the competent authorities can use the software themselves.

For the last 20 years, the development of dynamical mechanistic models of pollutants transport and water quality assessment in the drainage network river systems has been extensive ([2], [4], [5], [6]). However, most of the existing models do not meet all the requirements of the WFD. 
Some models have been first developed in order to address research topics such as the phytoplanktonic development ([7], [8], [9], [10]) or the nutrient loads from the watershed to the rivers [11].

But, the demand has rapidly increased to adapt the models to the stakeholders needs as a prospective tool for water management. Physicochemical models describing the behaviour of the whole river system, at various scales, was a response to this need ([12], [13], [14]). In that scope, the PEGASE model has been first developed on the Belgian Walloon region [15], then applied to major basins across Western Europe: Meuse, Mosel, Loire, Adour, Garonne, Scheldt, Seine, ... ([16], [17]). Amongst other studies, it has also been coupled to other models (e.g. hydrological models [18]). The most original feature of PEGASE is its capability to represent the watershed/river relationships and then to quantify the non-linear impact of pressures on the river ecosystem.

Many studies have showed the benefits, as well as the challenges, of stakeholder participation in environmental modelling ([19], [20]). The Pegase model has been developed in close collaboration with water agencies.

Stakeholders also needs friendly-to-use tools. An answer to this issue is to couple the model to a geographical information system (GIS) interface [21]. In the case of PEGASE, the model was coupled to a friendly Graphical User Interface (GUI) linked to a GIS to build the PEGOPERA modelling tool. The software allows, among other things, the users (scientists, water authorities ...) to perform pre-processing operations (to generate their databases), to pilot the model calculation and to visualize the simulation results.

The PEgOperA modelling tool, among many deterministic river systems models, complies with the requirements of the WFD.

\section{Methods}

\subsection{Characteristics of the PEgASE model and functionalities of the PEgOPERA software}

\subsubsection{The PEgase model}

The water quality model PEGASE (Figure 1) was built with the motivations to:

1) Better understand the aquatic ecosystem behaviour (hence the construction of a deterministic and physically based model which requires very few calibration when applied to new basins);

2) Structure knowledge (including the "input data");

3) Quantify the physically based "pressure - impact” relationships to help the authorities in charge of the surface water management in their process of decision making;

4) Extend the "river" models to explicitly take into account the influence of their watershed.

It is a physicochemical model describing the behaviour of whole river systems, at various scales, from tens to tens of thousands $\mathrm{km}^{2}$. The specificity of the model is its ability to work at a high spatial resolution not only for small river basins (water body level), but also for large drainage networks (> $100000 \mathrm{~km}^{2}$ ).

PEGASE is a process-oriented, physically based model; it consists of a set of partial differential equations describing the evolution in space and time of selected state variables: flow rate, temperature, concentrations of pollutants, nutrients, oxygen, biological populations.

The evolution equations contain parameters related to the mathematical formulation of physical, chemical and biological processes. The influence on the river of changes of management policy is reflected in a modification of the range of "control parameters" or "decision variables" (e.g. connection rates of urban releases to WWTPs).

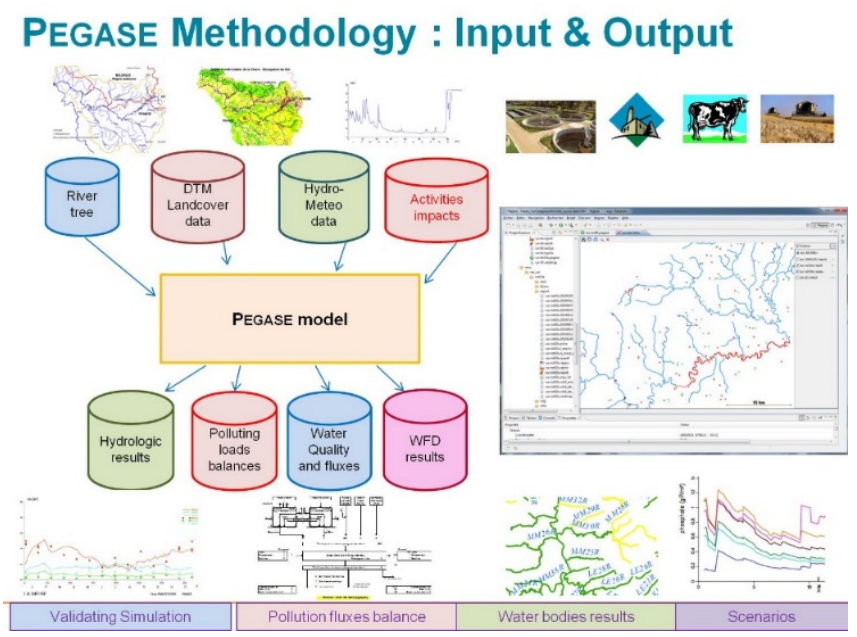

Figure 1. PEGASE Methodology: input data, user interface and results 


\subsubsection{The PEGOPERA software}

The PEgOpera software suite ([22]; Figure 2 from [23]) is composed of the water quality model PEGASE (currently version 6.3) and a friendly Graphical User Interface (GUI). The GUI provides the stakeholders with an easy-to-use operational modelling environment. The PEGOPERA software suite allows the use of the PEGASE model locally on PC, from data preparation to exploitation of results, including the simulation.

Since summer 2014, there are two complementary versions of PEGOPERA: 1) The "PEGOPERA PRO", containing all the features (see hereafter); 2) The "PEGOPERA CE" (Community Edition), simpler to handle and free of charges for non-profit usage (scientific research, education...).

Compared to the PRO version, the CE version is limited, but allows testing the software, and to calculate the water quality for large domains. The main differences are listed below:

1) CE version is free of charge and does not require an USB dongle;

2) The model (i.e. simulation run) is limited to a selection of 50 rivers and 7000 "nodes". It does not provide the "Mixing zone" feature, nor the "balances sheets" feature;

3) Edition via dedicated editor and/or use of some specific data file is not authorized in CE;

4) The preprocessing of base files is simplified in version CE (connectivity via closest point instead of steepest slope);

5) CE version is downloadable from the PEGASE web site (http://www.pegase.ulg.ac.be).

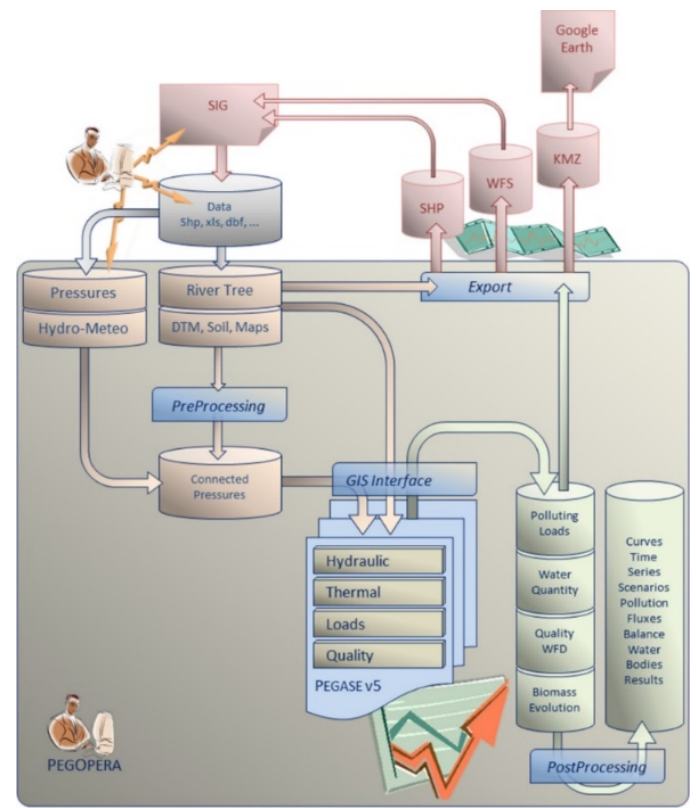

Figure 2. PEGOpERA software suite Architecture (from [23])

\subsection{Structure of the PEgASE model}

\subsubsection{The PEgASE submodels}

PEGASE is composed of four sub-models:

1) A hydrological and hydrodynamic sub-model, which calculates hydrodynamics variables (e.g. discharges, velocities, river depths, transfer times), for the whole river network (up to thousands of kilometres) and for the simulation period (usually one year), using daily discharge data from gauging stations. The way the flows are computed in the model is achieved by an inverse method using daily flow measurements at gauging stations (or from catalogs of characteristic flows). The river flows are then computed using the watershed surface, affected by corrections taking into account anthropogenic net water uptakes and imports (e.g. channels, irrigations). The calculations generally closely match the measured values. Velocities, river depths and transfer times are then computed using a Manning formulation ([23], [24]);

2) A sub-model dedicated to discharged loads (points as well as diffuse sources) of organic matter and major macro- and some micro-pollutants;

3) A thermal sub-model, which calculates water temperature from available daily data, taking into account thermal discharges from power plants and industries [25];

4) A sub-model dedicated to the calculation of the water quality and to the explicit description of the aquatic ecosystem behaviour, including ecological and biological processes: primary production, mortality and biomass 
respiration, organic matter degradation, oxygen cycle, sedimentation, nitrification and denitrification, reaeration... (Figure 3).

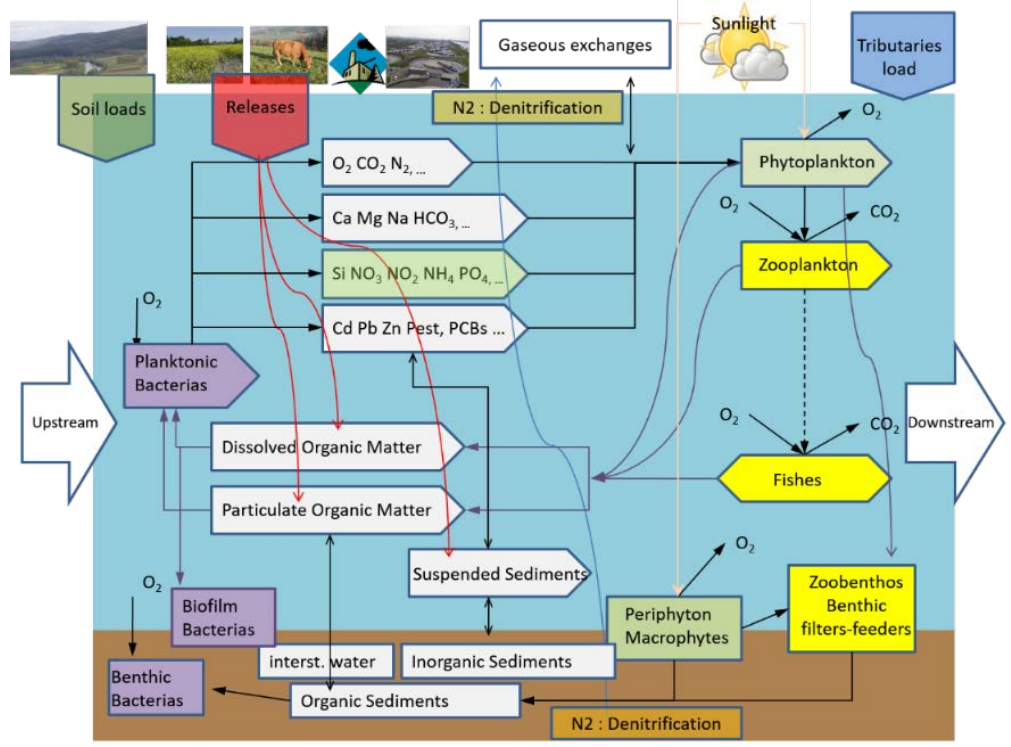

Figure 3. The aquatic ecosystem: main components and processes

\subsubsection{Spatial discretization}

To be able to simulate small river systems (at the scale of a WFD waterbody), as well as large river systems (e.g. at the scale of international river districts), taking explicitly into account interactions between tributaries, PEGASE needs to have a detailed description of the river network.

Typically, river networks simulated by PEGASE are based on digitized river networks available from geographical information systems. To be usable by PEGASE, some actions below need to be performed on the geographical coverages:

1) Identification and selection of the rivers to be simulated (basically, all rivers included in water bodies);

2) Check and correction of the geographical layer: check of the continuity of the rivers, correction of the flow directions, treatment of “difluences”;

3) Addition (if not present) or integration of topology information: e.g. confluences, hydrographic codification;

4) Selection of the nodes where data can be transmitted to the river system and where results can be extracted; the distance between two nodes can be customized (typically from $50 \mathrm{~m}$ to $500 \mathrm{~m}$ ).

PEGASE river networks can handle thousands of rivers: for example, the Loire application of PEGASE (118 000 $\mathrm{km}^{2}$, Figure 4) contains 5560 rivers (51 $720 \mathrm{~km}$ of rivers) and 138800 selected nodes. On the other hand, it is possible (e.g. to uses with the PEGOPERA Community Edition) to run the model with a single river.

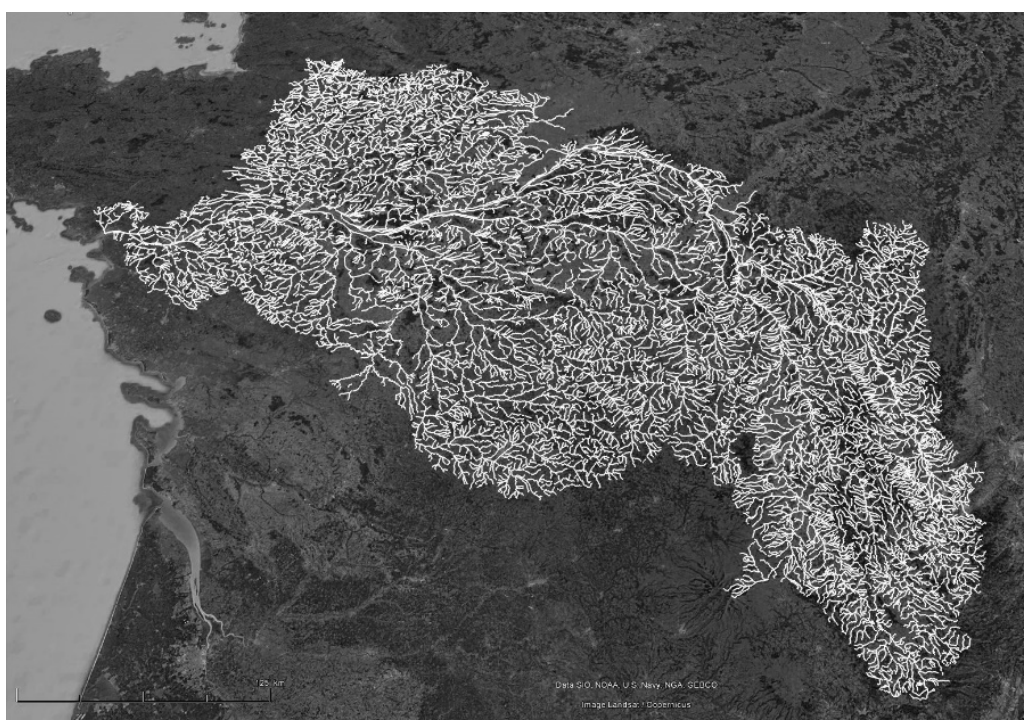

Figure 4. Loire network modelled by Pegase (5560 rivers, 51720 km of rivers) 


\subsubsection{Emission-Immission relationships}

One of the main issues to resolve is to connect all the river basin releases to the associated simulated river node. To do this, the river basin is divided into cells (usually $500 \mathrm{~m} \mathrm{x} 500 \mathrm{~m}$ or $1 \mathrm{~km} \mathrm{x} 1 \mathrm{~km}$ ). Using a Digital Elevation Model with a smaller grid cell (50 to $200 \mathrm{~m}$ ) and a steepest slope method, the river node where the center of each cell flows is computed (Figure 5). All releases contained inside the cell are supposed to be injected at this node.

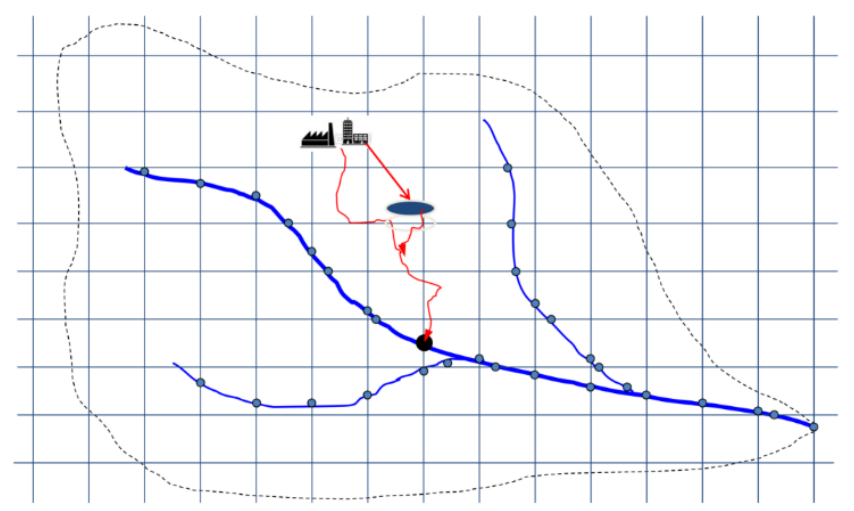

Figure 5. Steepest slope method (to establish the Emission-Immission relationships)

\subsubsection{Pollution loads}

In a structured way, PEGASE describes the urban releases, the industrial releases, the waste water treatment plants (WWTP), the links between these releases and the WWTPs, the abatement of pollution in the WWTPs, the loads due to livestock farming activities and the diffuse loads by soils (soil leaching functions).

The estimation of the urban releases is based on the inhabitant-equivalent concept (the individual pollution load in household sewage produced by one person in one day). Different types of urban loads (household, tourism, trading, school...) can be distinguished to take into account variation of fluxes during the year.

Industrial waste water discharges are estimated for the COD, N, P and micropollutants (kg/d), mainly from administrative inventories (for example for tax). The loads can be variable along the year (for example for seasonal industries such as sugar refineries, canning facilities). Dates of start / end of the discharge are also taken into account. If necessary, non-stationnary releases (time step variable down to one hour or less) can be taken into account.

Each urban or industrial release can be "connected" to a WWTP (Figure 6) for which abatements can be computed, either from measured values, or from typical values depending on the type of treatments realised. This method is better for simulating scenarios than a method consisting in directly using pollution loads measured at the outputs of the WWTPs.

\section{Point releases}

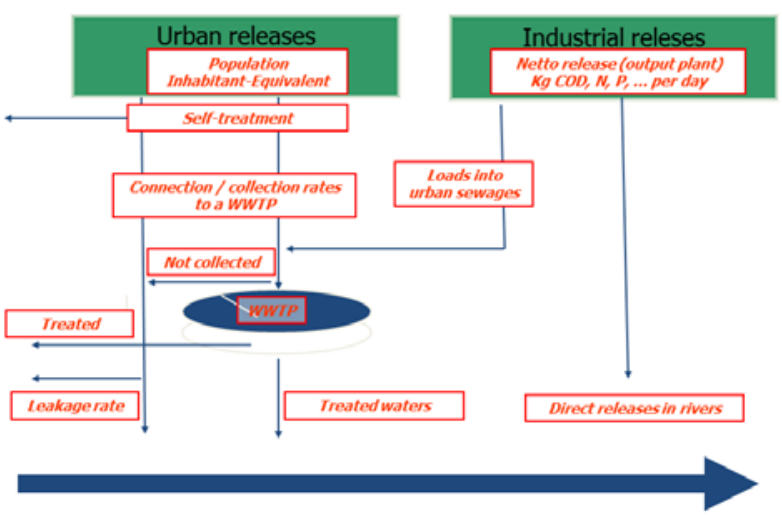

Figure 6. Representation of urban and industrials releases and waste water treatment plants

Loads due to livestock farming activities are taken into account on the bases of livestock inventories and a percentage of direct release, to estimates “accidental” losses. 
The diffuse loads by soils are estimated via semi-statistical functions, region specifics. This method is based on the fact that in non-polluted, homogeneous (in terms of soil occupation) and upper parts of the rivers, concentrations of the main diffuse pollutants (nitrates...) vary generally few during the year (Figure 7). In figure 7, Cultures 1: Aigre at Romilly (France, Loire basin, 313 km², 95 \% cultures); Cultures 2: Riedbrunnen at Colmar (France, Rhine basin, 4 km², 91 \% cultures); Meadows 1: Warchenne at Malmedy (Belgium, Meuse basin, 22 km², 69 \% meadows, intensive grazing); Meadows 2: Labiou at Labiou (France, Dordogne basin, 33 km², $74 \%$ meadows, extensive grazing); Forests 1: R. de Rebay at Mouzaive (Belgium, Meuse basin, 14 km², $97 \%$ forests); Forests 2: Furan at Le Bessat (France, Loire basin, 2 km², $89 \%$ forests)

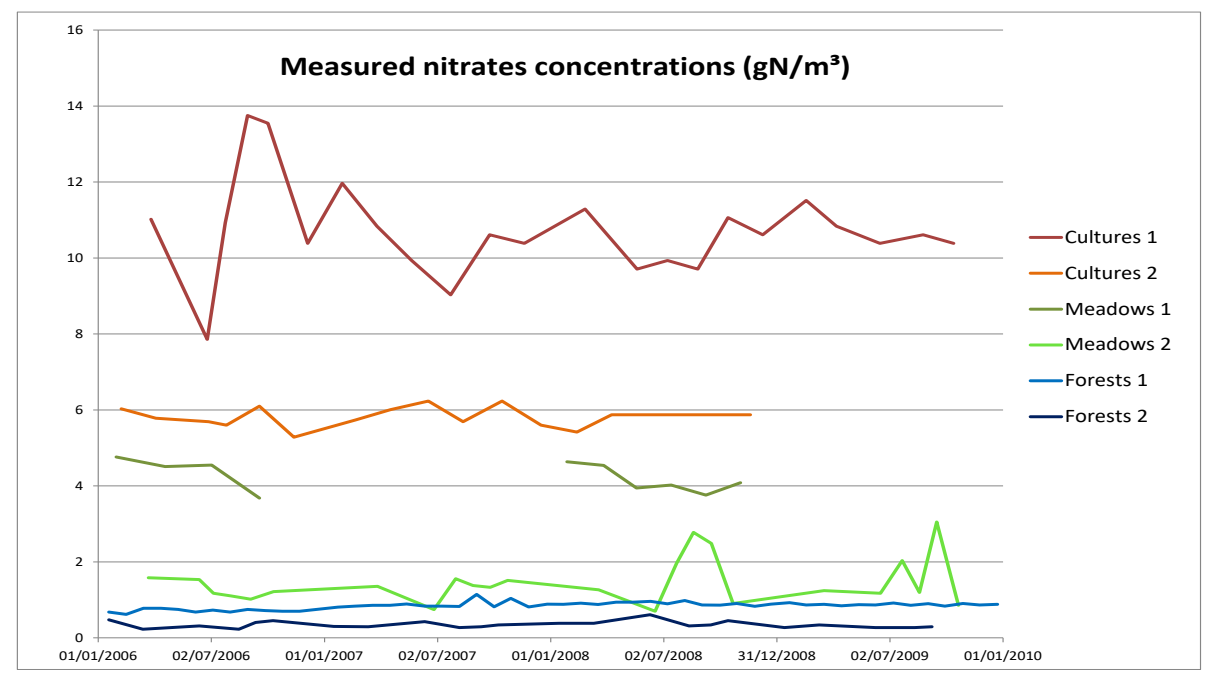

Figure 7. Nitrates concentrations in homogeneous upper river basins (years 2006-2009).

PEGASE thus uses a pragmatic approach for estimation of soil diffuse loads (Figure 8):

1) the domain is divided in cells (1 km x $1 \mathrm{~km}$ or less, see before);

2) In each cell, soil occupation repartition (culture, meadows, forests, urban) is computed (from CORINE Land Cover or other data);

3) For each soil occupation, concentrations (i.e. soils leaching functions) are estimated mainly on basis of measurement in upper part of rivers; these soil leaching functions can be regionalized (mainly for nitrates on cultivated soils);

4) "Globalized loads" (groundwater, hypodermic loads, runoff) are computed for each cell multiplying the soil leaching function $\left(\mathrm{g} / \mathrm{m}^{3}\right)$, the soil occupation $\left(\mathrm{m}^{2}\right)$ and the specific water discharge $\left(\mathrm{m}^{3} / \mathrm{m}^{2} . \mathrm{s}\right)$ computed by the hydrologic model of PEGASE (see below)

Due to the calibration with environmental measurements, this method gives very good results for estimating actual soil loads; a disadvantage of the method is that, since there is no pressure / impact relationships, soil leaching functions have few prediction power. To make agricultural scenarios, there is thus a need of results of other models like Epic ([26], [27]), Swat ([28][1], [29]), or from specific studies, or from expert opinions.

N.B.: PEGASE has the capability to be coupled to other models like soils models.

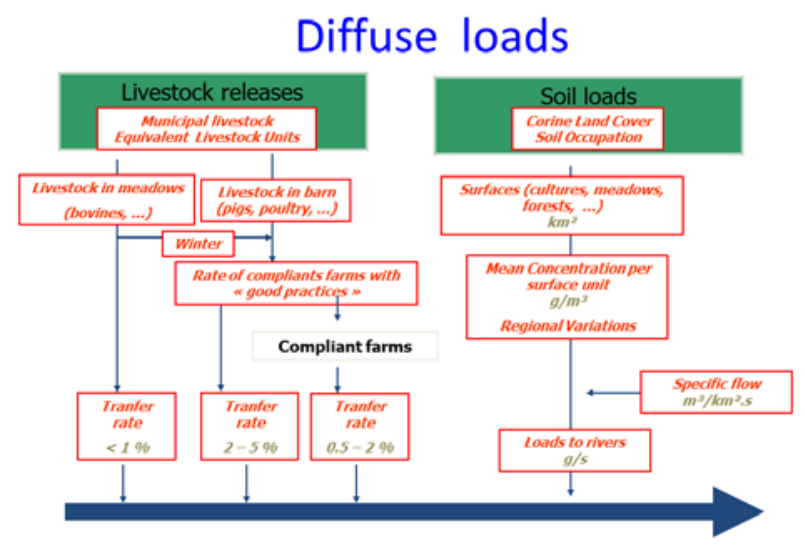

Figure 8. Representation of diffuse loads in the PEGASE model 


\subsubsection{The quality model}

PEGASE belongs to a new generation of models, being based on a detailed representation of the dynamics of the system, in particular the explicit calculation of the evolution of the various biomasses. Moreover, the structure of the PEGASE model is such that most of the parameters have a physical or biological significance (for example maximum rate of growth) and can thus be gauged separately by well targeted experimental measurements. One of the advantages is that PEGASE can thus be employed with few modifications and calibrations for various situations and different hydrographic networks.

The main postulate of the PEGASE model is that the physical, chemical and biological processes are the same in all rivers but depend on different environmental forcing variables (temperatures, flows, slopes, water depths), which leads to different states of the hydrosystem ([30],[31]).

The main processes and functionalities integrated into the PEGASE model are ([22]):

1) The calculation of hydrological and hydrodynamical variables (water discharges, velocities, water depths);

2) The calculation of water temperature;

3) The explicit calculation of the primary production (phytoplanktonic biomass) using a multi-species submodel ([10]; [32]);

4) The explicit calculation of the self-purification mechanisms in the rivers and the evolution of eutrophication (calculation of the bacterial biomasses and their activity);

5) The calculation of dissolved and particular organic matter (carbon, nitrogen, phosphorus), divided in three classes of biodegradability (rapidly, slowly and non-biodegradable);

6) The calculation of inorganic nitrogen (nitrates, nitrites, ammonium) and phosphorus (phosphates) compounds;

7) The calculation (at a time-step less than an hour) of dissolved oxygen concentrations, depending on the production fluxes (primary production), consumption fluxes (breaths, degradation of organic matter) and reaeration;

8) The calculation of the micropollutants: heavy metals, organic micropollutants... ([33]);

9) The calculation of physicochemical quality indices (e.g. French SEQ-Eau).

Due to its physically based characteristics, few processes or parameters need to be calibrated in the PEGASE model. Only the diffuse contribution by soils is estimated by a semi-statistical way using the concept of distributed soil leaching functions based on major macro-components and some micro-components (product of the specific flow by a concentration dependent on the land cover).

\subsection{User interface}

The PEGOPERA software result of the coupling of an enhanced version of the PEGASE model (version 6.x, rewritten in Oriented Object Fortran) with a friendly graphical user interface.

The coupling of the PEGASE model to a friendly graphical user interface has several interests as follows:

1) Easy-to-use and intuitive behaviour (in particular for a direct use by the stakeholders: scientists, administrations, Water Agencies);

2) User-friendly visualization of databases and results, allowing a more efficient analysis;

3) Help to the preparation of the databases and to the run of the simulations by producing explicative error messages (e.g. when encoded values exceed boundary ranges);

4) Bug tracker system and online help.

This interface allows among other things (Figure 9):

1) Modifying some input data files with specific editors (urban releases, industrial releases, waste water treatment plants, flows, parameters);

2) Generating files directly usable by PEGASE from these ones, exporting files dBase or excel compatible, shape files and Google Earth ${ }^{\mathrm{TM}} \mathrm{kmz}$ files;

3) Visualizing on maps the input data of the model (topographic base, discharges, connections release/waste water treatment plants...);

4) Creating and modifying simulation scenarios;

5) Carrying out simulations and comparing simulations between them;

6) Visualizing the results of these simulations and/or comparisons, river per river or in a global way (maps);

7) Exporting the results to ASCII, Excel or dBase files.

\subsection{Use of the model}

The model is a numerical tool to validate and check consistency of data at district (and thus international) level. The flexibility of the model allows the operator to choose the time (daily to yearly periods) and spatial (watershed, water body, district, region, country...) scales of the simulation and thus of the expected results.

\subsubsection{Data bases}

The model is fed by several required inputs: 
1) Ecological data to characterise bacteria, phytoplankton, zooplankton, macrophytes, shells;

2) Geographical data: digitalised watercourses (detailed discretisation of the network: e.g. 1 node every $200 \mathrm{~m}$ or less), digital terrain models, land cover, livestock, administrative reference frame;

3) Hydro-meteorological data: measurements of daily water flows, daily temperatures, and insolation;

4) Data related to human activities and releases (industrial, urban, water treatment plants...);

5) Other data such as water level, hydrodynamic measurements in some geo-localised points, anthropic singularities.

Most of the data are "administrative" data that administrations managing water systems should have in their databases: PEGOPERA does not need users to do specific measurements campaign (even if sometimes it could be useful).

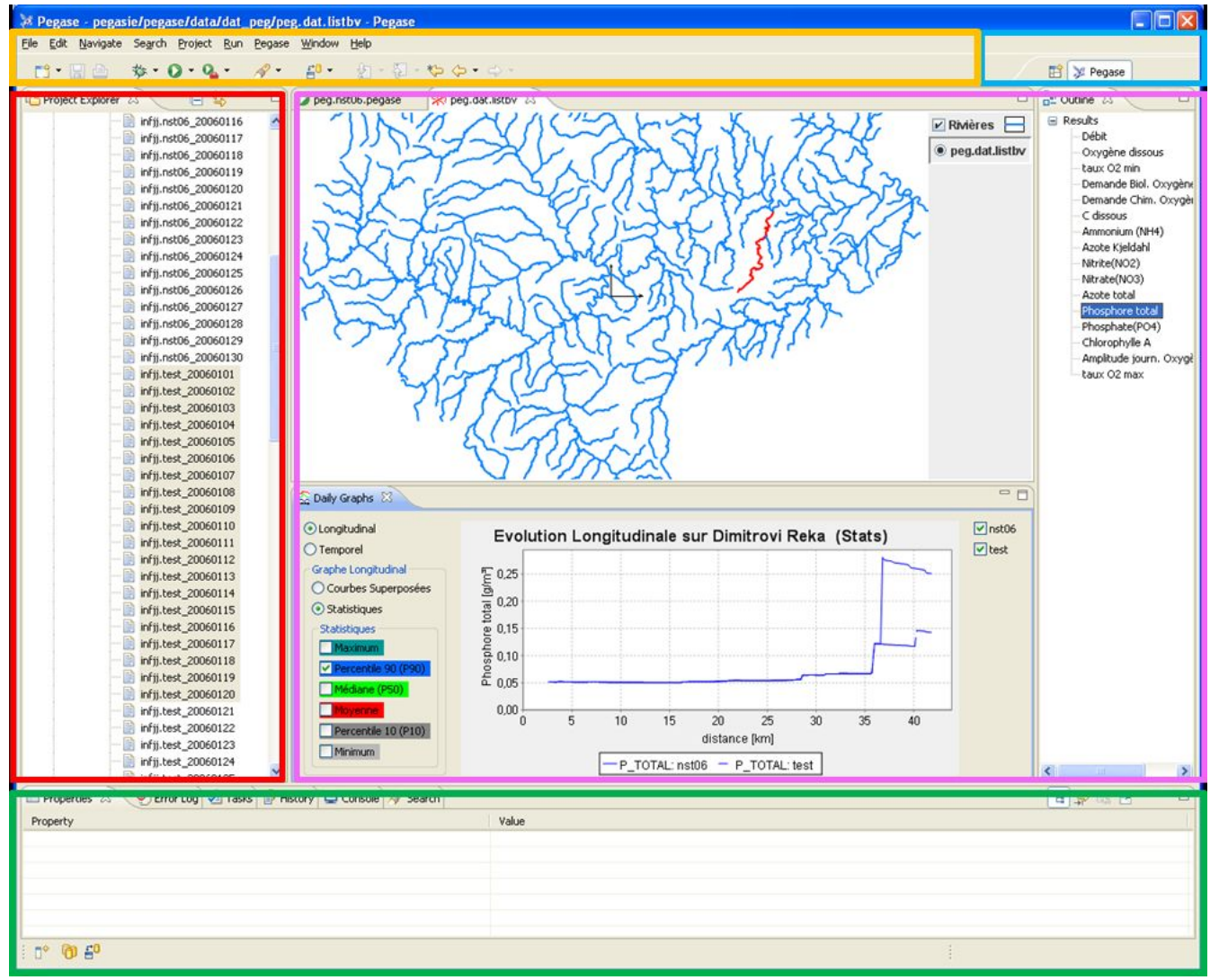

Figure 9. Screenshot of the PegOpera software and its different functional areas

\subsubsection{Calibration}

The model is process-oriented: very little calibration is needed. Most of the parameters have been determined experimentally ([34][33] for example) or based on a literature review; a few ones were fitted on specific basins by trial-errors in former studies.

For an application on a new river basin, only the soil leaching functions need to be calibrated.

\subsubsection{Validation}

In order to use environmental models effectively for management and decision-making, it is vital to establish an appropriate level of confidence in their performance [35]. After running the model on a historical period (one or many past years), the validation can be carried out by different methods:

1) Direct comparison between the calculated values and the measurements from the monitoring network (Figure 11).

2) Use of global validation utilities: these utilities (measurement/result curves (Figure 10), histograms, deviation maps, comparison indices) are designed to provide tools to validate the simulation results not "point by point" (e.g. on annual profiles in a given location), but taking all the measurements made on a basin, a sub basin, a river.

If the results of validation are not satisfactory, consolidations of the database or eventually of the modelled processes are necessary. Only when the validation step is satisfactory, prospective scenarios can be carried out with sufficient reliability. 


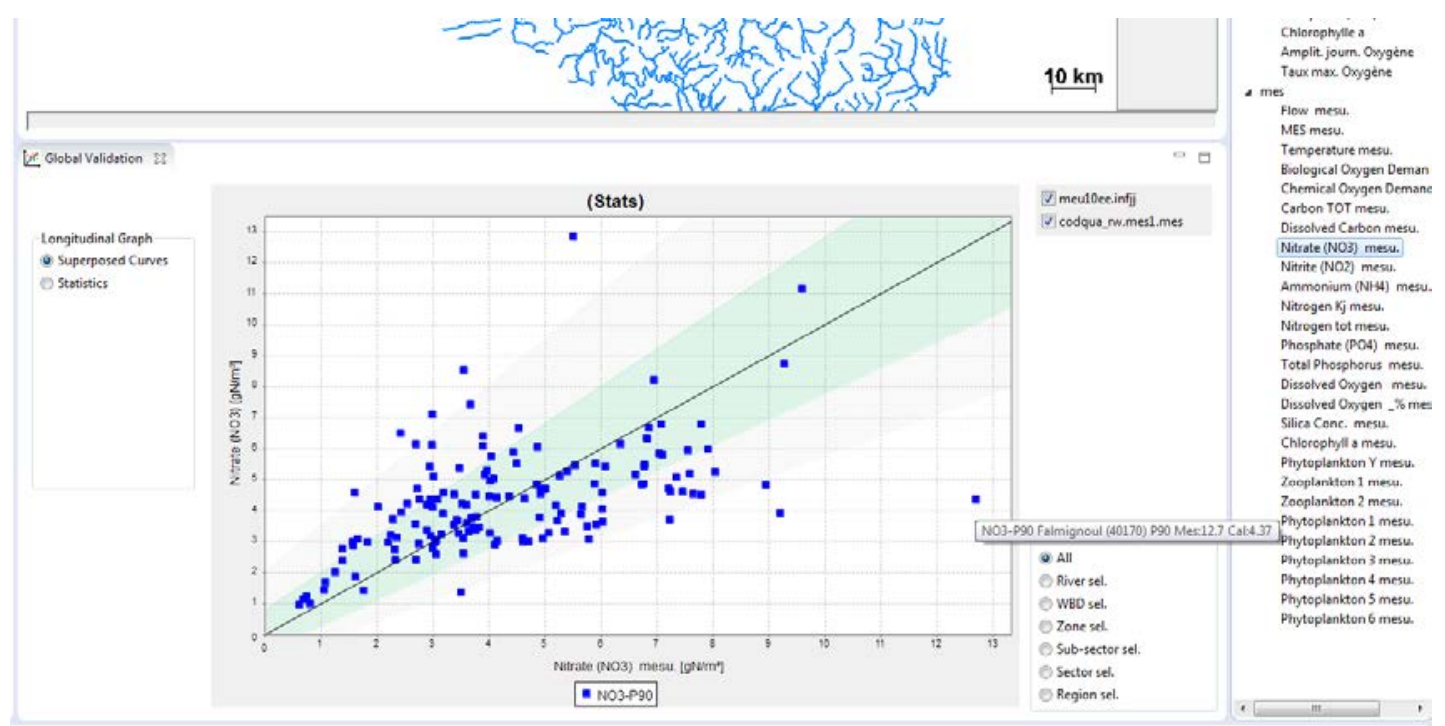

Figure 10. Global validation: regression plot (calculated results / measurements)

\subsection{Example of results}

The output of the software consists in tables, graphs and maps, showing the state of various quality parameters (dissolved oxygen, biological oxygen demand, chemical oxygen demand, nitrogen, phosphorus, chlorophyll a, micro-pollutants and indices) either at a specified time, along the river, or the temporal evolution at a given river node. It also provides maps, or animations of the temporal evolution of the results on the basin.

The main ways to exploit these results are also presented hereafter. They concern: 1) the creation of drawings (maps, longitudinal profile, annual evolutions); 2) the balance sheets creation at the outlets of the river and/or by water bodies; 3) the calculation of statistic values and the globalization per water bodies; 4) the export of results.

\subsubsection{Graphs outputs}

PEGOPERA can generate quasi automatically different types of graphs:

1) Time series graphs, with the evolution in time of the calculated variables at a given place (Figure 11);

2) Longitudinal graphs (from the source to the confluence of a river) for the calculated variables, either at a given moment (date), or for statistic values (percentiles 90, average values...) (Figure 12);

3) 2D maps, with coloured codes for a visualization (per class) (Figure 13). In the figure 13, on the upper part, 2D map with coloured codes for a visualization (per class), location of direct releases (urban, industrials, WWTP), links between urban and industrial releases and WWTPs (cyan lines) and simulates rivers (red lines); on the lower part, longitudinal profile for a river.

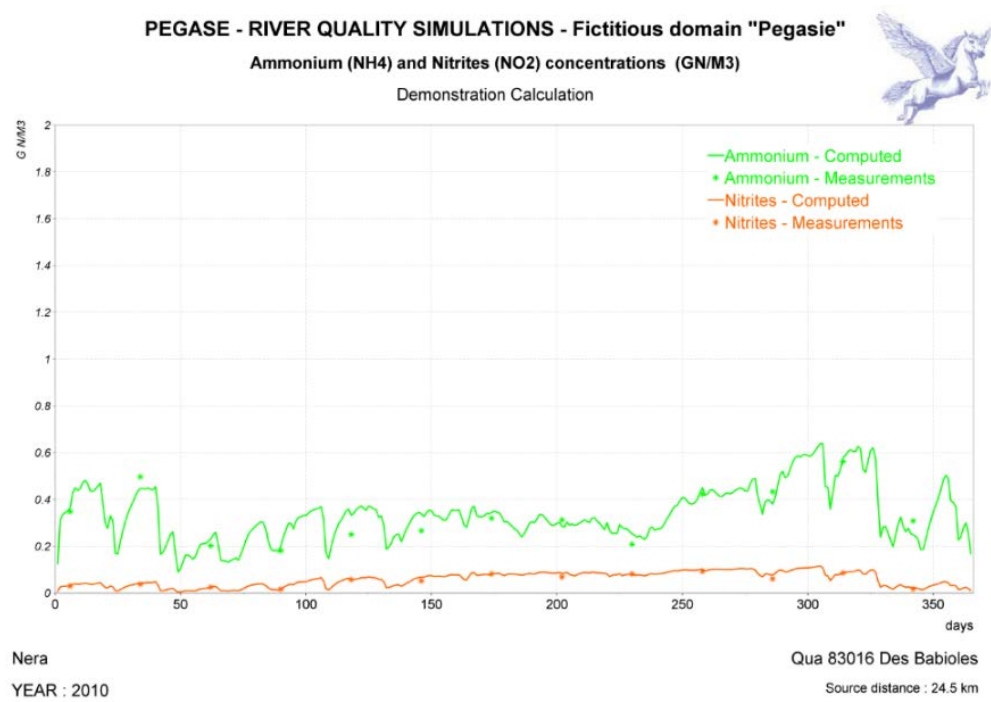

Figure 11. Example of batch time series graph with annual simulated and measured ammonium and nitrites concentrations 


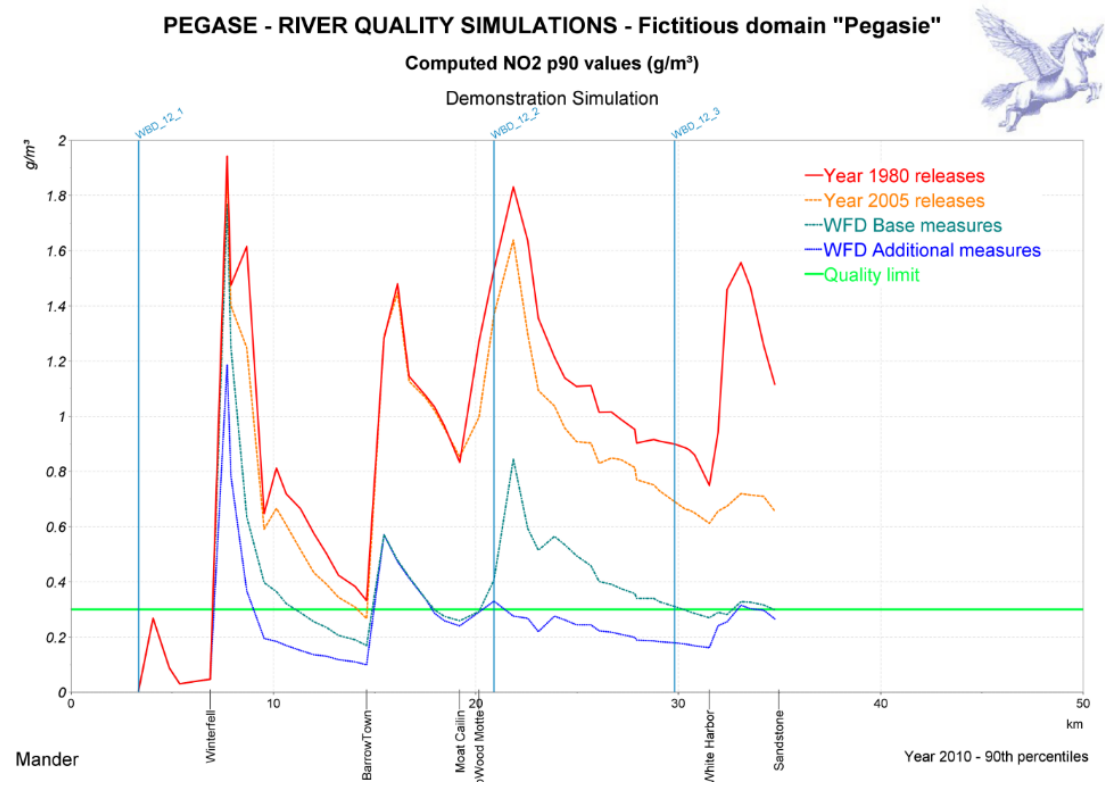

Figure 12. Example of batch longitudinal graph with 90th percentiles of annual nitrites concentration simulated for 4 scenarios; vertical cyan lines are the limits of waterbodies; horizontal green lines give the quality limit

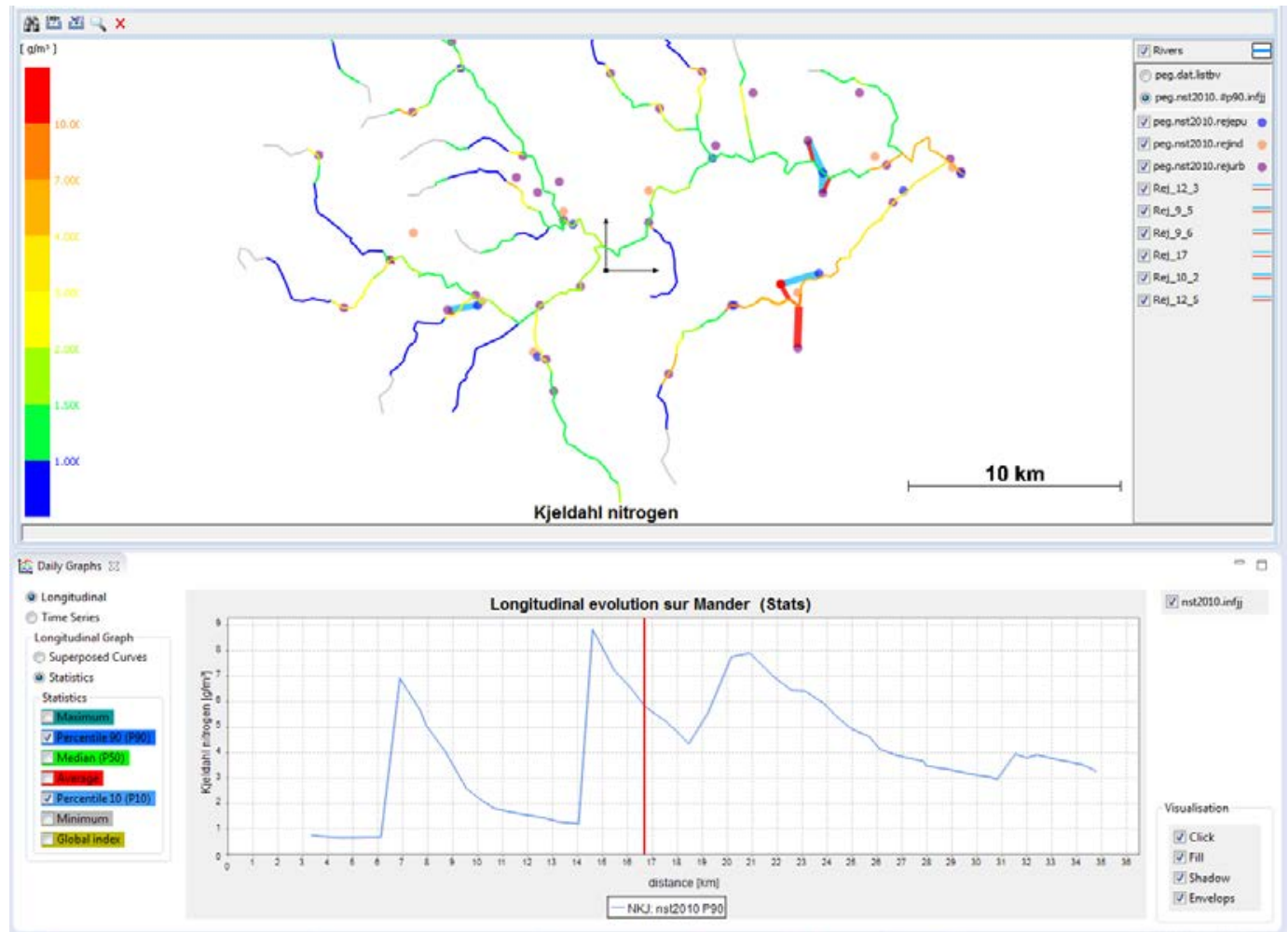

Figure 13. Example of an interactive graph for simulation analysis.

Time series graphs and Longitudinal graphs can be generated in two different ways: 1) in an interactive way, in the interface, to do a specific analysis of simulations in relation with 2Dmaps and the location of direct releases, (Figure 13, lower part); 2)in a "batch" mode, to do, in a single command, several graphs for many rivers and variables. (Figure 11 \& Figure 12)

For validation purpose, measurements of the physico-chemical variables can be added on the longitudinal graphs and time series graphs (Figure 11); drawing the results of different simulations permits the direct comparison of scenarios, and thus, for example, the effect of base and additional measures taken (Figure 12).

For longitudinal graphs, there is a possibility to add "incidents": tributaries, releases, measurement points, waterbodies limits (Figure 12). 
Results can thus be viewed as well in details (water body scale or less, for a depth analysis of results) as at a macroscopic scale (district scale for example, see Figure 14 with the Meuse IRBD)

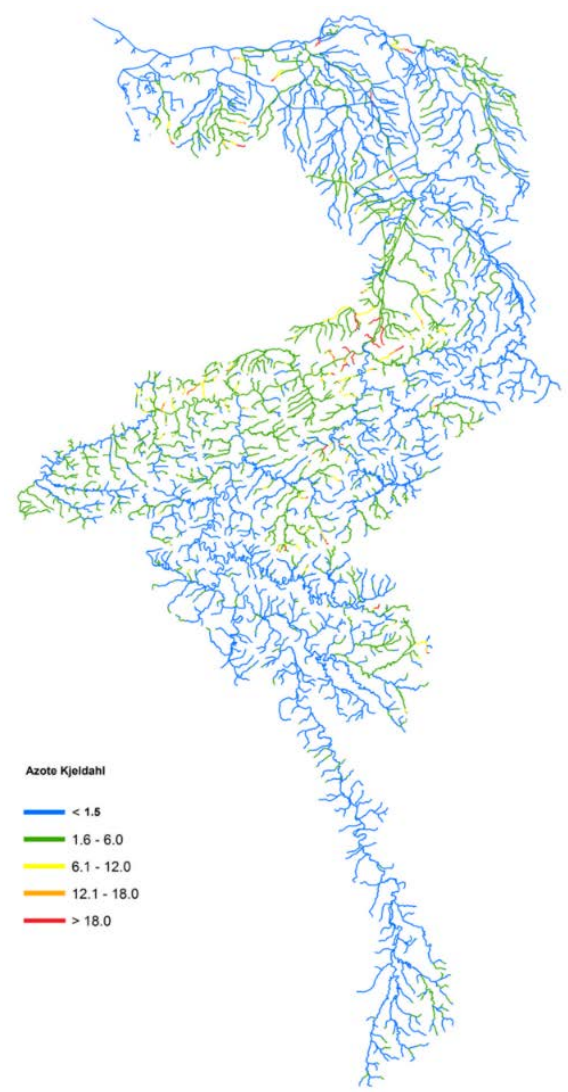

Figure 14. Quality map for the entire hydrographic network of the IRBD Meuse, 90th centile of Kjeldahl Nitrogen concentrations $\left(\mathrm{gN} / \mathrm{m}^{3}\right)$, year 2005 (From [17] )

\subsubsection{Balance sheets generation}

PEGASE can generate balance sheets per catchment sub-basin, per river, per waterbody, on the basis of all the calculations that are realized during a simulation (Figure 15).

These balance calculations allow assessing the flux of organic matter (carbon), of nitrogen and of phosphorus compounds for periods specified by the simulation non-stationary settings (for example, annual mean flux, summer flux). If it is not really a validation, these balances however allow globally seeing quite easily the origin of different pollutions present in the aquatic network.

\subsubsection{Calculation of statistical values}

Most assessments of the water quality are performed using statistical values of the annually measured values in one point. It is the case, for example of the SEQ-Eau indices that are (normally) calculated on the percentiles 90 of the calculated values.

If PEGOPERA is used in the non-stationary mode, the concentrations in the river system are calculated every day of the year on the whole modeled river network: it is thus in principle easy to calculate statistical values of the concentrations simulated on the network.

\subsubsection{Calculations of quality indices}

Quality indices can be calculated directly by the PEGASE model, using the extended SEQ-Eau definition.

\subsubsection{Calculations per waterbody}

WFD impose to reach the "good quality" for water bodies. PEGASE computes the water quality for each node of the computed rivers (a node every 200-400 m). It is thus necessary to "globalize" the PEGASE results per waterbody (Figure 16). This globalization can be done in several ways, such as simple arithmetic average, a weighted average on the width of the rivers, a weighted average on the flows, or the consideration of a specified percentile on all the points belonging to the water body. 


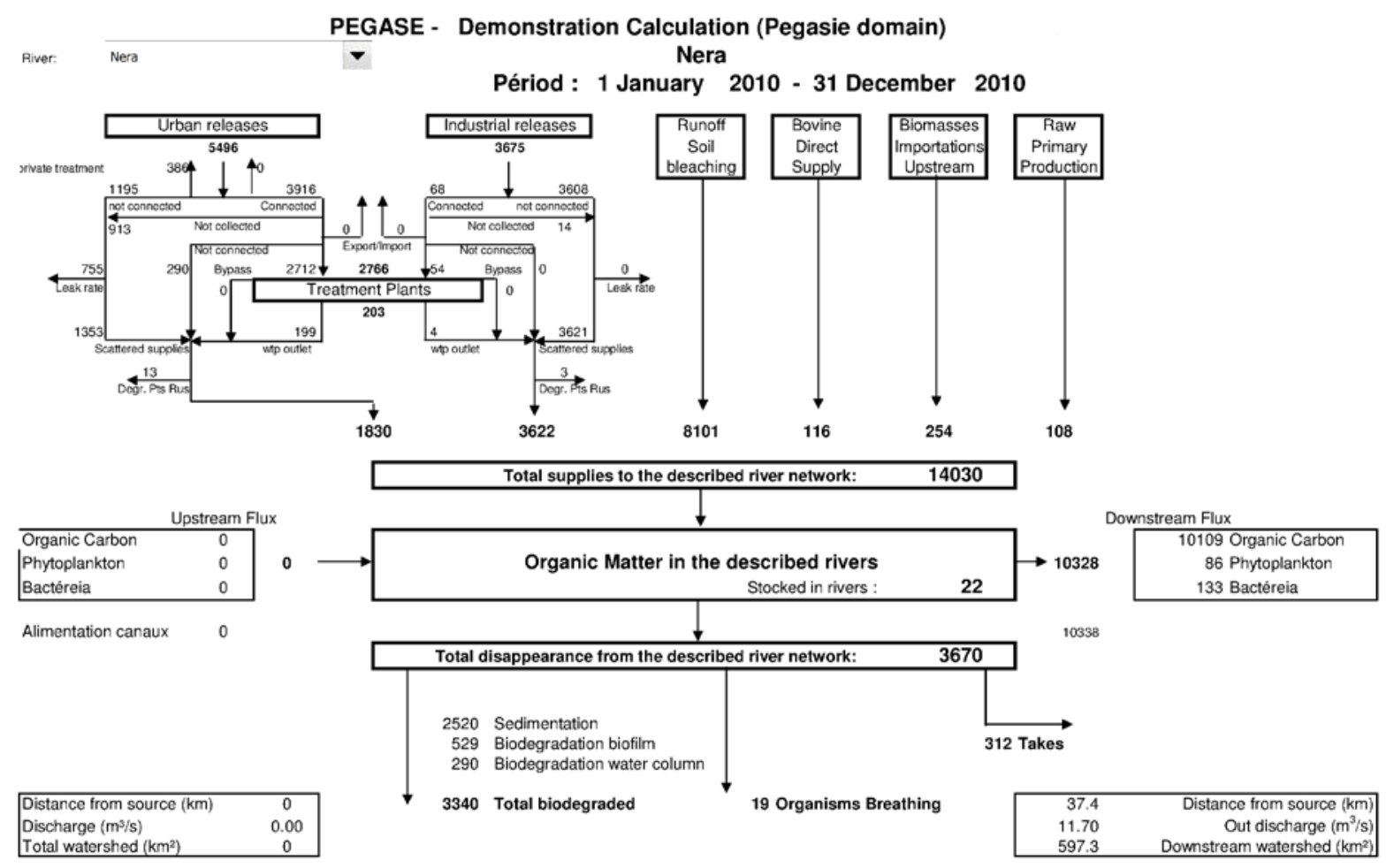

PEGASE : Organic matter yield (kg C/day)

Figure 15. Annual balance sheet for the organic matter for a river sub-basin: raw and net releases, fluxes in the river, disappearance in the river network...
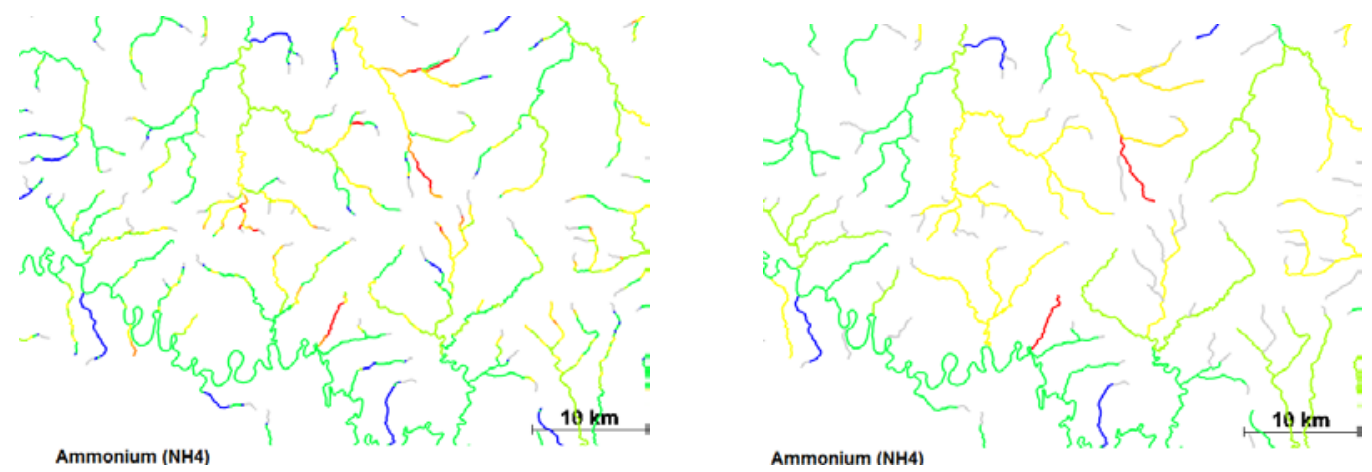

Figure 16. Example of results per node (left) and globalized per water body (right)

\section{Discussion}

The model presented here is deterministic and proposes a detailed representation of physicochemical processes controlled by environmental conditions, based on a set of kinetic equations representing the dynamics of the system and the evolution of the biological processes. The parameters are not fitted as they have physical, chemical or biological signification (they are not site-dependent except those associated with the soil functions).

Models of this kind are often opposed to more empirical models based on a much simpler representation of process kinetics (e.g. QUAL2E, [36]). A great advantage of deterministic models is that any discrepancy between observed and modelled variables in a validation/verification step cannot be resolved by a better calibration of the models parameters, but explicitly indicates an area where either our knowledge of the control factors (e.g. databases, pressures) or our understanding of the processes is inadequate. Calibrating and validating the PEGOPERA software on a new basin is a time consuming task, because validation not only concerns the model itself, but also and primarily the data (e.g. flows and releases).

The PEGASE model has been built for scientific purpose (understanding of the aquatic ecosystem) but also to be helpful for decision makers. Included in the PEGOPERA software suite, PEGASE is today very useful for administrations which have to implement the DCE. 
Most of the developments of the model have been done in consultation with users. The development of the Pegase model and the PegOpera software has been done continually for more than 20 years and is continuing. The main axes of development for the next years are:

1) Scientific developments, which include sediments, micropollutants (heavy metals, emergent micropollutants and so on) and Urban releases during rain events.

2) Interoperability development (integrated modelling, coupled simulations with soils, groundwater models)

3) Interface development (ease of use of the model, compliancy with WFD requirements)

\section{Conclusions}

PEGOpera proved to be an efficient tool for helping in surface water management from local up to the international district level. Already used by several basin management competent authorities, the model structures the river ecosystem knowledge and allows:

1) The assessment of the rivers quality, by non-stationary, accurate and physically based simulation, on the complete river-tree and the comparison of results with discrete measurements points for calibration/validation. These results lead to a much more accurate understanding of the river systems (e.g. the pressure/impact relationships, the relative importance of driving forces, the lotic ecosystem);

2) Assess the impact of proposed measures to enhance the quality of targeted water bodies, by performing simulations of scenarios and assessing the cost/efficiency ratio of each solution;

3) Assess the impact of climatic changes on the future river quality;

4) Ensure the consistency of the data at an international level;

5) Extrapolate discrete measurements (e.g. monitoring system, in time and space) for each water body, by a physically based calculation.

PEGOPERA is therefore an operational numerical tool for WFD implementation from local to global scale, providing direct usable results to the stakeholders.

\section{Acknowledgements}

The authors wish to express their thanks to the Administrations that participate in the development of the PEgASE Model and the PEgOPERA software (sorted by order of involvement in the research): Operational Directorate General for Agriculture, Natural Resources and the Environment, Walloon Public Service, Belgium (SPW-DGARNE-DGO3) (http://spw.wallonie.be/?q=dgo3); Rhin-Meuse Water Agency (AERM), France (http://www.eau-rhin-meuse.fr/); The Water Management Administration, Grand Duchy of Luxembourg (http://www.eau.public.lu/); Flemish Environment Agency (VMM), Belgium (http://www.vmm.be/); LoireBretagne Water Agency (AELB), France (http://www.loire-bretagne.fr/); Adour-Garonne Water Agency (AEAG), France (http://www.eau-adour-garonne.fr/); Artois-Picardie Water Agency (AEAP), France (http://www.eauartois-picardie.fr/); Seine-Normandie Water Agency (AESN), France (http://www.eau-seine-normandie.fr/)

\section{References}

[1] Biswas AK. Integrated water resources management: a reassessment: a water forum contribution. Water international. 2004;29(2):248-256.

[2] Loucks DP, Van Beek E. Water resources systems planning and management: an introduction to methods, models and applications. UNESCO; 2005. p.698.

[3] Directive 2000/60/EC of the European Parliament and of the Council of 23 October 2000 establishing a framework for Community action in the field of water policy. Official Journal of the European Communities L 327.p. 72. https://eur-lex.europa.eu/legal-content/EN/TXT/PDF/?uri=OJ:L:2000:327:FULL\&from=EN.

[4] Tsakiris G, Alexakis D. Water quality models: An overview. European Water. 2012;37:33-46.

[5] Wang Q, Li S, Jia P, Qi C, Ding F. A review of surface water quality models. The Scientific World Journal. 2013.

[6] Sharma D, Kansal A. Assessment of river quality models: a review. Reviews in Environmental Science and Bio/Technology. 2013;12(3):285-311.

[7] Billen G, Garnier J, Hanset P. Modelling phytoplankton development in whole drainage networks: the RIVERSTRAHLER model applied to the Seine river system. Hydrobiologia. 1994;289: 119-137.

[8] Gamier J, Billen G, Coste M. Seasonal succession of diatoms and Chlorophyceae in the drainage network of the Seine River: Observation and modeling. Limnology and Oceanography. 1995;40(4):750-765. 
[9] Schöl A, Kirchesch V, Bergfeld T, Müller D. Model-based analysis of oxygen budget and biological processes in the regulated rivers Moselle and Saar: modeling the influence of benthic filter feeders on phytoplankton. Hydrobiologia. 1999;410: 167-176.

[10] Everbecq E, Gosselain V, Viroux L, Descy JP. Potamon: a dynamic model for predicting phytoplankton composition and biomass in lowland rivers. Water Research. 2001;35(4):901-912.

[11] Behrendt H, Kornmilch M, Opitz D, Schmoll O, Scholz G. Estimation of the nutrient inputs into river systems-experiences from German rivers. Regional Environmental Change. 2002;3(1-3):107-117.

[12] Dupont J, Smitz J, Rousseau AN, Mailhot A, Gangbazo G. Use of digital decision support system tools for water management. Revue des Sciences de l’Eau. 1998;11 (spécial): 5-18(in French).

[13] Billen G, Garnier J. Nitrogen transfer through the Seine drainage network: a budget based on the application of the RIVERSTRAHLER model. Hydrobiologia. 1999; 410:139-150.

[14] Rousseau AN, Mailhot A, Turcotte R, Duchemin M, Blanchette C, Roux M, Dupont J, Villeneuve JP. GIBSI - An integrated modelling system prototype for river basin management. Hydrobiologia. 2000; 422-423: 465475.

[15] Smitz JS, Everbecq E, Deliège JF, Descy JP, Wollast R, Vanderborght JP. PEGASE : a methodology and a simulation tool for the management of surface water quality. Tribune de l'eau. 1997;588(4):73-82. (in French).

[16] Deliège JF, Grard A, Everbecq E, Weingertner P, Conan C, Salleron JL, Coulon O, De Guibert O. PEGASE, A model dedicated to Surface Water Quality Assessment that helps stakeholders implementing the WFD. European Geosciences Union General Assembly 2011. Vienna, Austria;2011.

[17] Grard A, Everbecq E, Magermans P, Bourouag M, Deliège JF. Transnational modelling of the Meuse District with PegOpera simulation software. International Journal of River Basin Management. 2014;12(3):251-263.

[18] Safiolea E, Baki S, Makropoulos C, Deliège JF, Magermans P, Everbecq E, Gkesouli A, Stamou A, Mimikou M. Integrated modelling for river basin management planning. Proceedings of the Institution of Civil Engineers: Water Management. 2011;164(8):405-419.

[19] Voinov A,Bousquet FR. Modelling with stakeholders. Environ. Model. Softw. 2010; 25: 1268 - 1281.

[20] Voinov A, Kolagani N, McCall MK, Glynn PD, Kragt ME, Ostermann FO, Pierce SA, Ramu P. Modelling with stakeholders-next generation. Environmental Modelling \& Software. 2016;77:196-220.

[21] Ruelland D, Billen G, Brunstein D, Garnier J. SENEQUE: a multi-scaling GIS interface to the Riverstrahler model of the biogeochemical functioning of river systems. Science of the Total Environment. 2007;375(13):257-273.

[22] Deliège JF, Everbecq E, Magermans P, Grard A, Bourouag M, Blockx C. PEGASE, a software dedicated to surface water quality assessment and to European database reporting. In: Proceedings of the European Conference of the Czech Presidency of the Council of the EU Towards eEnvironment, Opportunities of SEIS and SIZE: Integrating Environmental Knowledge in Europe. Brno, Czech Republic: Masaryk University; 2009.p. 24-32.

[23] Deliège JF. Model integration method adapted to multicompartmental hydrological systems. [PhD Thesis]. University of Liège; 2013.p.266. (in French).

[24] Chapra SC. Surface water-quality modeling. Long Grove: Waveland Press;2014. p.844.

[25] Smitz JS. Thermal model of river, natural temperature and thermal discharges. Application to the Meuse river in Liège. Research and Technology for the Environment. Ed. CEBEDOC. Liège; 1976.p.117-137(in French).

[26] Gassman PW, Williams JR, Benson VR, Izaurralde RC, Hauck LM, Jones CA, Atwood JD, Kiniry JR, Flowers JD. Historical development and applications of the EPIC and APEX models. CARD Working Paper 05-WP 397. Center for Agricultural and Rural Development, Iowa State University; 2005.

[27] Izaurralde RC, Williams JR, Mcgill WB, Rosenberg NJ, Jakas MQ. Simulating soil C dynamics with EPIC: Model description and testing against long-term data. Ecological Modelling. 2006;192(3-4):362-384.

[28] Arnold JG, Srinivasan R, Muttiah RS, Williams JR. Large area hydrologic modeling and assessment part I: model development 1. JAWRA Journal of the American Water Resources Association. 1998;34(1):73-89.

[29] Arnold JG, Fohrer N. SWAT2000: current capabilities and research opportunities in applied watershed modelling. Hydrological Processes: An International Journal. 2005;19(3):563-572.

[30] Polus E, Flipo N, De Fouquet CH, Poulin M. Geostatistics for assessing the efficiency of a distributed physically-based water quality model: application to nitrate in the Seine River. Hydrol. Process. 2011; 25: 217-233.

[31] Reichert P, Borchardt D, Henze M, Rauch W, Shanahan P, Somlyódy L, Vanrolleghem P. River water quality model no. 1 (RWQM1): II. Biochemical process equations. Water Science and Technology. 2001;43(5):1130.

[32] Descy JP, Leitao M, Everbecq E, Smitz JS, Deliège JF. Phytoplankton of the River Loire, France: a biodiversity and modelling study. Journal of Plankton Research. 2011;34(2):120-135. 
[33] Deliege JF, Everbecq E, Magermans P, Grard A, Bourouag T, Blockx C, Smitz J. PEGASE, an integrated river/basin model dedicated to surface water quality assessment: application to cocaine. Acta Clinica Belgica. 2010;65(sup1):42-48.

[34] Descy JP, Servais P, Smitz JS, Billen G, Everbecq E. Phytoplankton biomass and production in the River Meuse (Belgium). Water Research. 1987;21(12):1557-1566.

[35] Bennett ND, Croke BFW, Guariso G, Guillaume JHA, Hamilton SH, Jakeman AJ, Marsili-Libelli S, Newham LTH, Norton JP, Perrin C, Pierce SA, Robson B, Seppelt R, Voinov AA, Fath BD, Andreassian V. Characterising performance of environmental models. Environ. Model. Softw.2013;40:1-20.

[36] Brown LC, Barnwell TO. Enhanced stream water quality models, QUAL2E and QUAL2E UNCAS. Documentation and User's TechReport. Department of Civil Engineering, Tufts University, Medford, MA 02155. Environmental Research Laboratory Office of Research and Development. U.S. Environmental Protection Agency. EPA/600/3-87/007. 1987.

(C) 2019 by the author(s). This work is licensed under a Creative Commons Attribution 4.0 International License (http://creativecommons.org/licenses/by/4.0/). Authors retain copyright of their work, with first publication rights granted to Tech Reviews Ltd. 